\title{
EXPERIMENTAL STUDY ON INFLUENCE OF STACK EFFECT ON FIRE IN THE COMPARTMENT ADJACENT TO STAIRWELL OF HIGH RISE BUILDING
}

\author{
Wen Xi SHI ${ }^{\mathrm{a}, \mathrm{b}, \mathrm{c}}$, Jie JI ${ }^{\mathrm{a}}$, Jin Hua SUN ${ }^{\mathrm{a}, \mathrm{c}}$, S. M. LO ${ }^{\mathrm{b}, \mathrm{c}}$, Lin Jie LI ${ }^{\mathrm{a}}$, Xiang Yong YUAN ${ }^{\mathrm{a}}$ \\ ${ }^{a}$ State Key Laboratory of Fire Science, University of Science and Technology of China, Hefei 230026, China \\ ${ }^{b}$ Department of Civil and Architectural Engineering, City University of Hong Kong, Hong Kong, China \\ ${ }^{c}$ USTC-CityU Joint Advanced Research Centre, Suzhou, China
}

Received 26 May 2012; accepted 28 Jun 2012

\begin{abstract}
In this paper, to study the influence of stack effect on fire in the compartment adjacent to a stairwell, a set of experiments were conducted by varying the pool size, top vent state and bottom vent size in a 1/3 scaled 12-layer-stairwell configuration. The phenomenon of methanol flame tilting in the fire room was observed and studied. Results showed that the flame tilt angle increases with an increase of $\mathrm{Ri}^{-1}$. The temperatures of hot gases in the fire room decrease due to the cooling effect of fresh air induced by stack effect. The mass loss rate of methanol fuel is influenced by fresh air flow sucked into fire room due to stack effect. On the basis of the experimental results, we conclude that the velocity of air flow into fire room is proportional to $1 / 3$ power of the heat release rate in the stairwell.
\end{abstract}

Keywords: stack effect, high-rise buildings, fire behaviour, compartment fire.

Reference to this paper should be made as follows: Shi, W. X.; Ji, J.; Sun, J. H.; Lo, S. M.; Li, L. J.; Yuan, X. Y. 2013. Experimental study on influence of stack effect on fire in the compartment adjacent to stairwell of high rise building, Journal of Civil Engineering and Management 20(1): 121-131. http://dx.doi.org/10.3846/13923730.2013.802729

\section{Introduction}

Many high rise buildings have been constructed in the world. The fire safety of these buildings has drawn public attention due to the occurrence of many catastrophic fires (Chow 2005; Guo et al. 2009, 2010). A notable example is the MGM Grand Hotel fire in 1980 (Best, Demers 1982), 85 people died in this fire, with 68 victims located on the upper floors far away from the ground floor where the fire occurred, one significant reason of this phenomenon is that the hot smoke movement from the lower to the upper floors was induced by the stack effect of stairwell in the building (Klote, Fothergill 1983; Council... 1992). Stack effect is the phenomenon observed in cold weather when a tall building acts like a chimney, with air entering through openings in lower floors, flowing upward in the building, and leaving through openings in upper floors (Tamura 1994; Klote 1994; Evans, Klote 2003). Stack effect results from the difference in density between warm inside air and cold outside air (Barrett, Locklin 1969). It's a common construction that the door face stair hall or lift lobby in high-rise residential building (Chow, Hung 2003; Chow, C., Chow, W. 2009). For this kind of building structure, in case a fire occurs in the room adjacent to stair hall or lift bobby, the fire-induced smoke will not only spread horizontally along the room and corridor ceilings, but also move vertically under the influence of stack effect. The air flow pattern in the compartment where fire starts has significant influence on the fire behaviours and smoke movement. Chow (2003, $2010,2011)$ reported that the duration of a fire depends on the fire load and available ventilation. If there is sufficient fuel in the compartment, a small fire, once ignited, will grow. Adding to that, a plenty of fresh air is sucked into the fire room by stack effect. Big fires might occur due to providing fresh air contributing to burning large amount of combustibles and causing severe damage. So it is worthy to research the influence of stack effect on fire in the compartment adjacent to stairwell to improve the safety level of high-rise residential buildings structure.

A number of authors have studied stack effect of stairwell or shaft in building spaces in the last decades (Zukoski 1995; Cooper 1998; Zhang et al. 2006; Mowrer 2009; Ji et al. 2012a, b, 2013; Li 2013); however, little attention has been focused on the influence of stack effect on fire in the compartment adjacent to stairwell. Sun (2009) investigated the smoke movement in a full-scale six-storey stairwell induced by a fire in an adjacent compartment and discovered that the flame was tilted to the stairwell due to stack effect, but he did not further explore the flame shape of fire and the temperature of hot smoke in the room. The air flow induced by stack effect is natural convection. Another kind of natural air convection, external wind, effect on compartment fire has been discussed by several researchers. The effect of wind speed on the movement of hot smoke in four different buildings has been studied by Porch and Trebukov (2000). Huang 
et al. (2009) explored the fire growth process in a reduced-scale compartment under different external wind conditions. It was found that external wind had two opposing effects. One was to promote combustion within the compartment and thus raised the temperature, the other was to blow away and dilute the combustible gases in the compartment and decrease the temperature, or hasten its extinction. Chen et al. (2008) also reported that the ambient wind had two contradictory effects on the compartment fire, and then inferred a critical wind velocity to prevent hot smoke to outflow from the upstream vent, which was regarded to influence enclosure fire behaviour greatly. Roh et al. (2007a, b) investigated the effect of longitudinal ventilation velocity on the burning rate in tunnel fires and discovered that the increase in ventilation velocity reduced the burning rate of the methanol fuel. In fact, external wind is different from stack effect action on compartment fire. For the former, external wind is existent before fire occurred and the velocity of air flow is almost constant. For the latter, stack effect is almost nonexistent before fire occurs, and then the velocity of air flow acted on the fire plume is instantaneous, which is related to the heat release rate, ventilation state and building geometry. Therefore, the fire behaviour is more complex in the compartment adjacent to the stairwell. The flame shape and the heat transfer mechanism are significantly changed and then the fire spread process is influenced by the stack effect action.

In this paper, a set of experiments were conducted to study the influence of stack effect on fire in the compartment adjacent to stairwell in a 1/3 scaled 12-layerstairwell configuration (Sun 2009). The temperatures and fire properties in the compartment were investigated.

\section{Experiments}

The experimental facility consists of stair, atria and room, as shown in Figure 1. The dimensions of the $1 / 3$ scale building model with 12 levels is $12.2 \mathrm{~m}$ high, $2.6 \mathrm{~m}$ long, and $1.5 \mathrm{~m}$ wide. The ground floor is $1.2 \mathrm{~m}$ high and the other floors are $1.0 \mathrm{~m}$ high. The cross-sections of stair, atria and room are $1.5 \times 1.0 \mathrm{~m}, 0.8 \times 0.8 \mathrm{~m}, 0.8 \times 0.8 \mathrm{~m}$, respectively. Each floor has three doors with the size of $0.6 \mathrm{~m}$ (height) $\times 0.4 \mathrm{~m}$ (width). The left and front sidewalls of model are a fire-resistant glass (12 mm thickness) for observation, and the other parts are constructed of steel plate with thickness of $2 \mathrm{~mm}$.

The temperatures of hot gases of room, atria and stairwell were measured by $47 \mathrm{~K}$-type fine wire thermocouples, including 25 thermocouples in the room and 12 thermocouples in the stairwell. The detailed location of the thermocouples is shown in Figure 2. Four velocity probes of hot-wire anemometers (Kanomax, KA12) at a $10 \mathrm{~cm}$ vertical interval were installed $5 \mathrm{~cm}$ away from the right side of the first floor door 3 to measure the airflow speed. All the pools were placed on an electronic balance to measure the transient mass of the burning pool fire with sampling intervals of $1 \mathrm{~s}$. The weight resolution of the balance is $0.1 \mathrm{~g}$. A Digital Vidicon and a Digital Camera were used to record the flame development of the pool fire in the room.

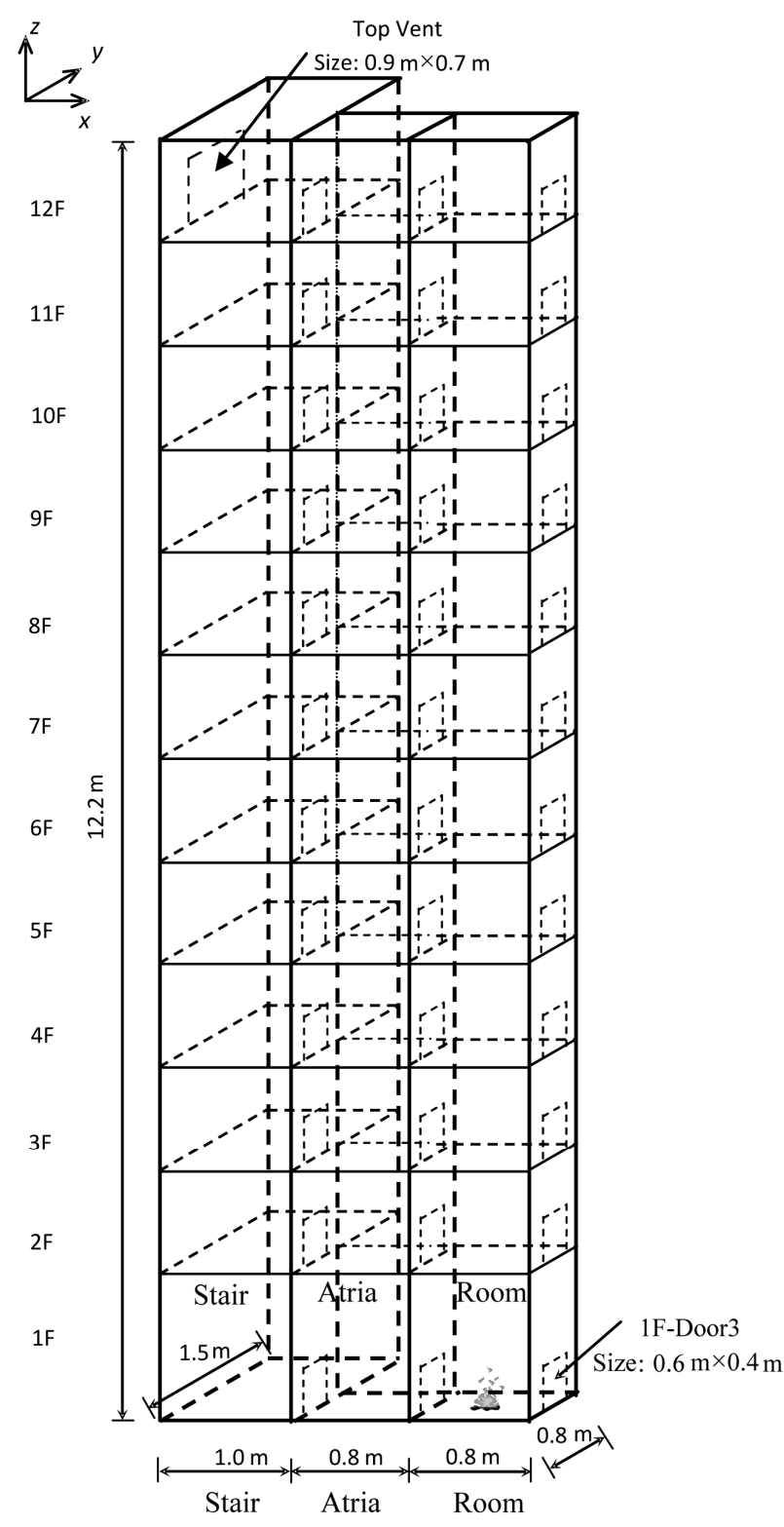

Fig. 1. Schematic of 12-layer-stairwell configuration

There were 12 cases in the experiments. Methanol was used as fuel and ambient temperature was about 5$7{ }^{\circ} \mathrm{C}$. Fire source was located in the centre of the room on the ground floor. Only three doors on the ground floor were open, the other doors were close. The top vent with size $0.9 \mathrm{~m}$ (height) $\times 0.7 \mathrm{~m}$ (width) was located in left side of 12-layer. The detailed experimental cases are shown in Table 1.

\section{Results and discussions}

\subsection{Compartment fire behaviours}

The development of flames of different pool fires was observed in those experiments. From the video recording, it can be found that the flame inclined towards the direction of stairwell under the influence of stack effect after ignition for a while, which was also reported by Sun (2009), but he did not conduct further discussion. 
a)

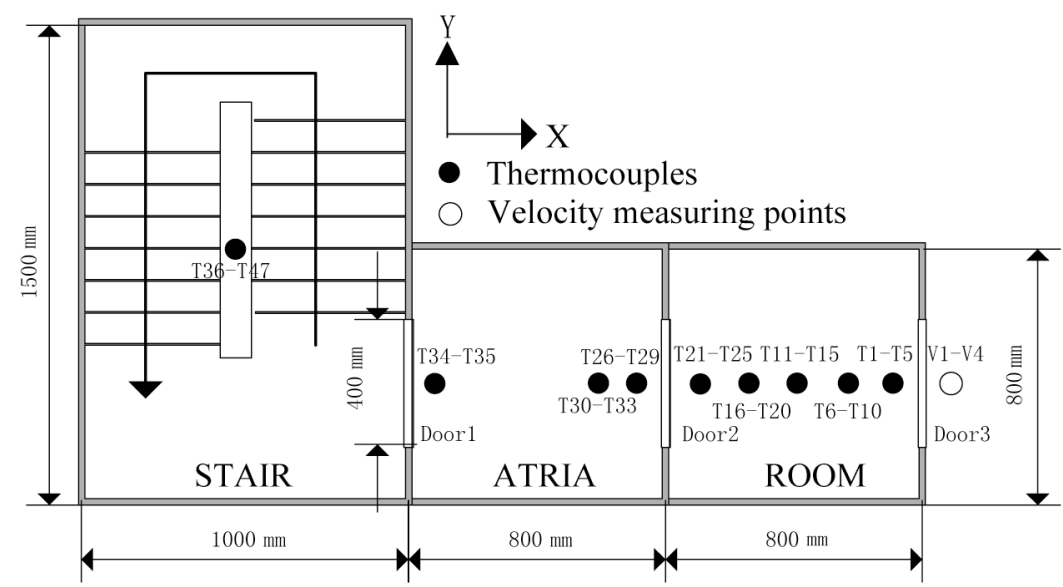

b)

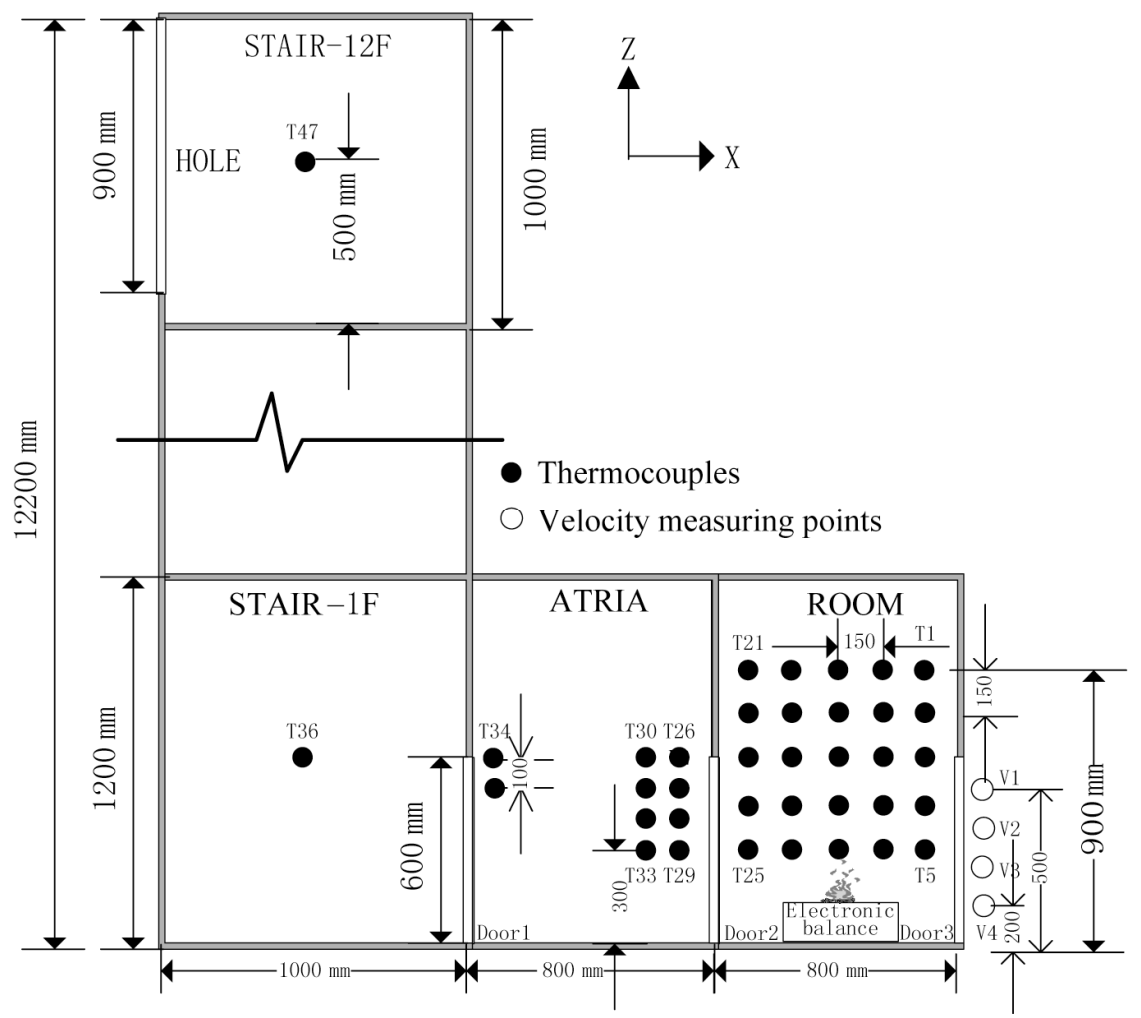

Fig. 2. Locations of thermocouples and velocity measuring points: a) Top view; b) Side view

Table 1. Experimental details

\begin{tabular}{|c|c|c|c|c|c|c|}
\hline Case & Pool Size & 1F-Door 3 Size (height $\times$ width) & Top Vent & $V(\mathrm{~m} / \mathrm{s})$ & Flame tilt angle $\theta$ & $R i^{-1}$ \\
\hline A1 & $10 \mathrm{~cm} \times 10 \mathrm{~cm}$ & \multirow{4}{*}{$0.3 \mathrm{~m} \times 0.4 \mathrm{~m}$} & \multirow{4}{*}{ Open } & 0.6 & $62^{\circ}$ & 0.51 \\
\hline $\mathrm{A} 2$ & $15 \mathrm{~cm} \times 15 \mathrm{~cm}$ & & & 0.78 & $71^{\circ}$ & 0.58 \\
\hline A3 & $20 \mathrm{~cm} \times 20 \mathrm{~cm}$ & & & 0.98 & $73^{\circ}$ & 0.69 \\
\hline A4 & $25 \mathrm{~cm} \times 25 \mathrm{~cm}$ & & & 1.03 & $60^{\circ}$ & 0.6 \\
\hline B1 & $10 \mathrm{~cm} \times 10 \mathrm{~cm}$ & \multirow{4}{*}{$0.6 \mathrm{~m} \times 0.4 \mathrm{~m}$} & \multirow{4}{*}{ Open } & 0.53 & $59^{\circ}$ & 0.4 \\
\hline B2 & $15 \mathrm{~cm} \times 15 \mathrm{~cm}$ & & & 0.67 & $67^{\circ}$ & 0.43 \\
\hline B3 & $20 \mathrm{~cm} \times 20 \mathrm{~cm}$ & & & 0.88 & $72^{\circ}$ & 0.55 \\
\hline B4 & $25 \mathrm{~cm} \times 25 \mathrm{~cm}$ & & & 0.95 & $61^{\circ}$ & 0.52 \\
\hline $\mathrm{C} 1$ & $10 \mathrm{~cm} \times 10 \mathrm{~cm}$ & \multirow{4}{*}{$0.6 \mathrm{~m} \times 0.4 \mathrm{~m}$} & \multirow{4}{*}{ Close } & 0.24 & $34^{\circ}$ & 0.08 \\
\hline $\mathrm{C} 2$ & $15 \mathrm{~cm} \times 15 \mathrm{~cm}$ & & & 0.39 & $31^{\circ}$ & 0.14 \\
\hline $\mathrm{C} 3$ & $20 \mathrm{~cm} \times 20 \mathrm{~cm}$ & & & 0.46 & $41^{\circ}$ & 0.15 \\
\hline $\mathrm{C} 4$ & $25 \mathrm{~cm} \times 25 \mathrm{~cm}$ & & & 0.62 & $47^{\circ}$ & 0.22 \\
\hline
\end{tabular}




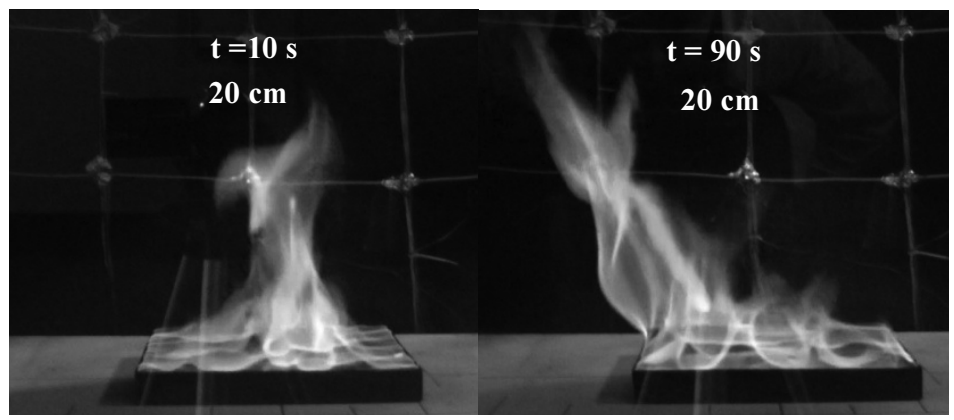

a) $10 \mathrm{~s}$

b) $90 \mathrm{~s}$

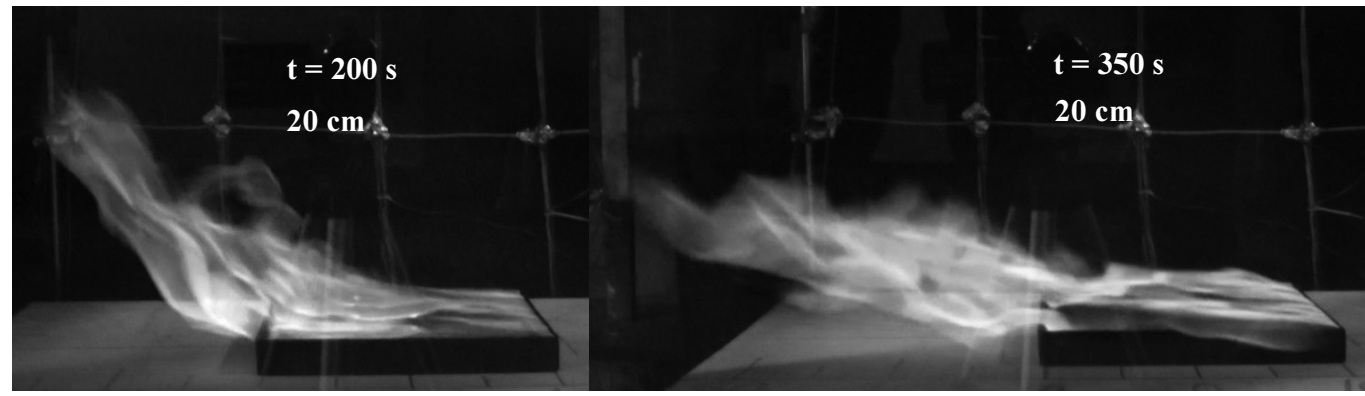

c) $200 \mathrm{~s}$

d) $350 \mathrm{~s}$

Fig. 3. Flame shape at different time of Case B3 (Top Vent open, Door 3 Size: $0.6 \mathrm{~m} \times 0.4 \mathrm{~m}$ )

The flame inclination may ignite distant combustibles and enhance the possibility of fire spread in the horizontal direction. Knowledge of flame behaviour has been playing an important role in the fire safety design. The typical flame shapes of Case B3 are shown in Figure 3. At the beginning of the fire, the methanol burned quietly and the flame did not tilt towards any directions in the compartment, as shown in Figure 3(a). The hot smoke symmetrically flowed out from the doors at two sides of compartment, and then the temperatures in stairwell rose. At about $90 \mathrm{~s}$, the flame began to incline towards the direction of the stairwell due to the occurring stack effect. As time passed, the stack effect was more significant with an increase of temperature in the stairwell from $90 \mathrm{~s}$ to $350 \mathrm{~s}$. After $350 \mathrm{~s}$, the flame almost attached to the ground, as shown in Figure 3(d). Figure 4 shows the velocity of fresh air flowing into fire room from door 3 in Case B3. It can be seen that the velocity of air flow increases continually from $0 \mathrm{~s}$ to $350 \mathrm{~s}$ and then remains almost unchanged.

To quantitatively compare flame shapes in different cases, a flame tilt angle $\theta$ (shown in Fig. 5) is often defined as the angle between the centreline of flame region and vertical direction. The typical instantaneous images of flame were captured from the experimental videos in a relatively steady state when the velocity of air flow into fire room got the maximum value and remained unchanged for a period of time, then the flame tilt angle $\theta$ in all cases could be determined.

The calculated flame tilt angle $\theta$ and the mean air flow speed $V$ through Door 3 in a steady state of different cases are shown in Figure 6. As shown in Figure 6, the flame in the cases with top vent closed (Case C1-C4) also inclined to the direction of stairwell. It may be caused by

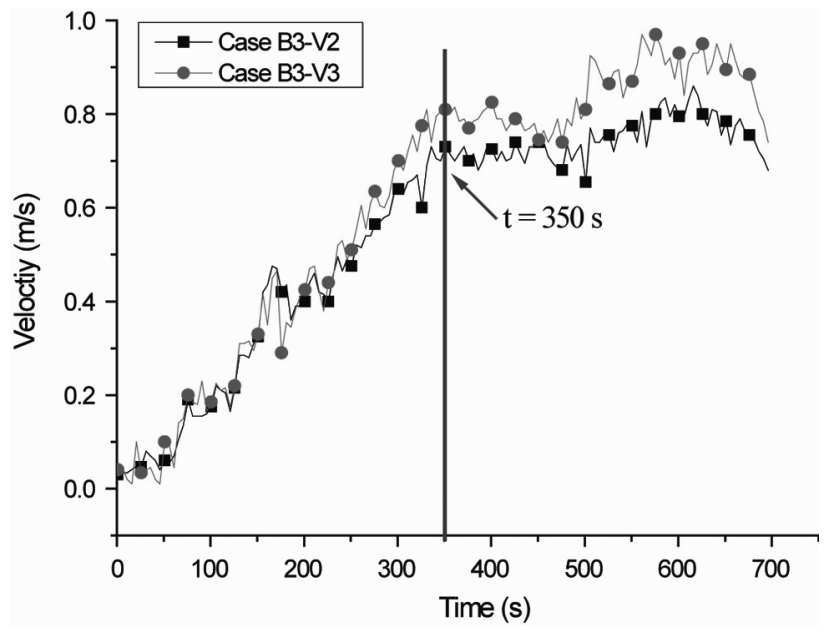

Fig. 4. Velocity of airflow into fire room of Case B3 (Pool: $20 \mathrm{~cm}$, Top Vent open, Door 3 Size: $0.6 \mathrm{~m} \times 0.4 \mathrm{~m}$ )

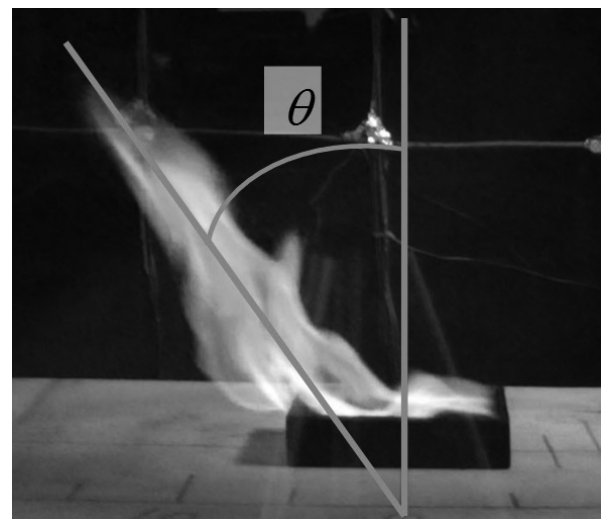

Fig. 5. Schematic of flame tilt angle $\theta$ 
different state of air entrainment at two sides of the fire plume. For a fire room adjacent to the stairwell with top vent closed (Case C1-C4), fuel consumes continually surrounding air (oxygen) after ignition. At the beginning, the quantity of air entrained from any direction is almost equal, and then the fire plume stands vertically. As time passed, the side of fire plume pointing to the stairwell could not obtain enough fresh air and only the side pointing to the Door 3 could. Therefore the flame inclined to the direction of stairwell, resulting from the pressure difference between both sides of fire source. Sun (2009) and Chow, C. and Chow, W. (2009) also observed that the flame was tilted to the stair-well in their experiments conducted in a full-scale six-storey stairwell without top opening. This is different with the case that the fire plume in single compartment with symmetrical opening does not incline to any directions in a quiescent condition described in reference (Chen et al. 2008).

It is shown from the Figure 6 that the flame tilt angle $\theta$ is remarkably enlarged in the cases with top vent open (Case A1-A4 and Case B1-B4), compared with the cases with top vent closed (Case C1-C4). When top vent is open, the hot smoke flowing into stairwell could easily induce the occurrence of the stack effect, resulting in larger velocity of air flowing into the fire compartment. Contrarily, in the cases with closed top vent (Case C1$\mathrm{C} 4)$, the stack effect could not be formed and only the buoyancy drove the hot smoke to spread vertically. Therefore, the velocities of air flowing into compartment from the door 3 in the cases with top vent open are much larger, resulting in larger flame tilt angle $\theta$.

The flame tilt angle $\theta$ of case A1-A4 and case B1B4 are compared in Figure 6. It is shown that the flame tilt angle $\theta$ of cases with the same pool size is very close. In addition it can be found that an increase in pool size leads to an increase in air speed $V$ flow into fire room. The velocity $V$ in the cases with pool size of $25 \mathrm{~cm}$ (Case A4 and Case B4) is the maximum. However, it is shown that the flame tilt angle $\theta$ first increases and then decreases with an increase in pool size for the same ventilation state. The flame tilt angle $\theta$ of $20 \mathrm{~cm}$ pool size (Case A3 and Case B3) reached a maximum. To interpret this phenomenon and analysis air flow effect on flame shape of pool fire, a non-dimensional number (Richardson number) is introduced as follow.

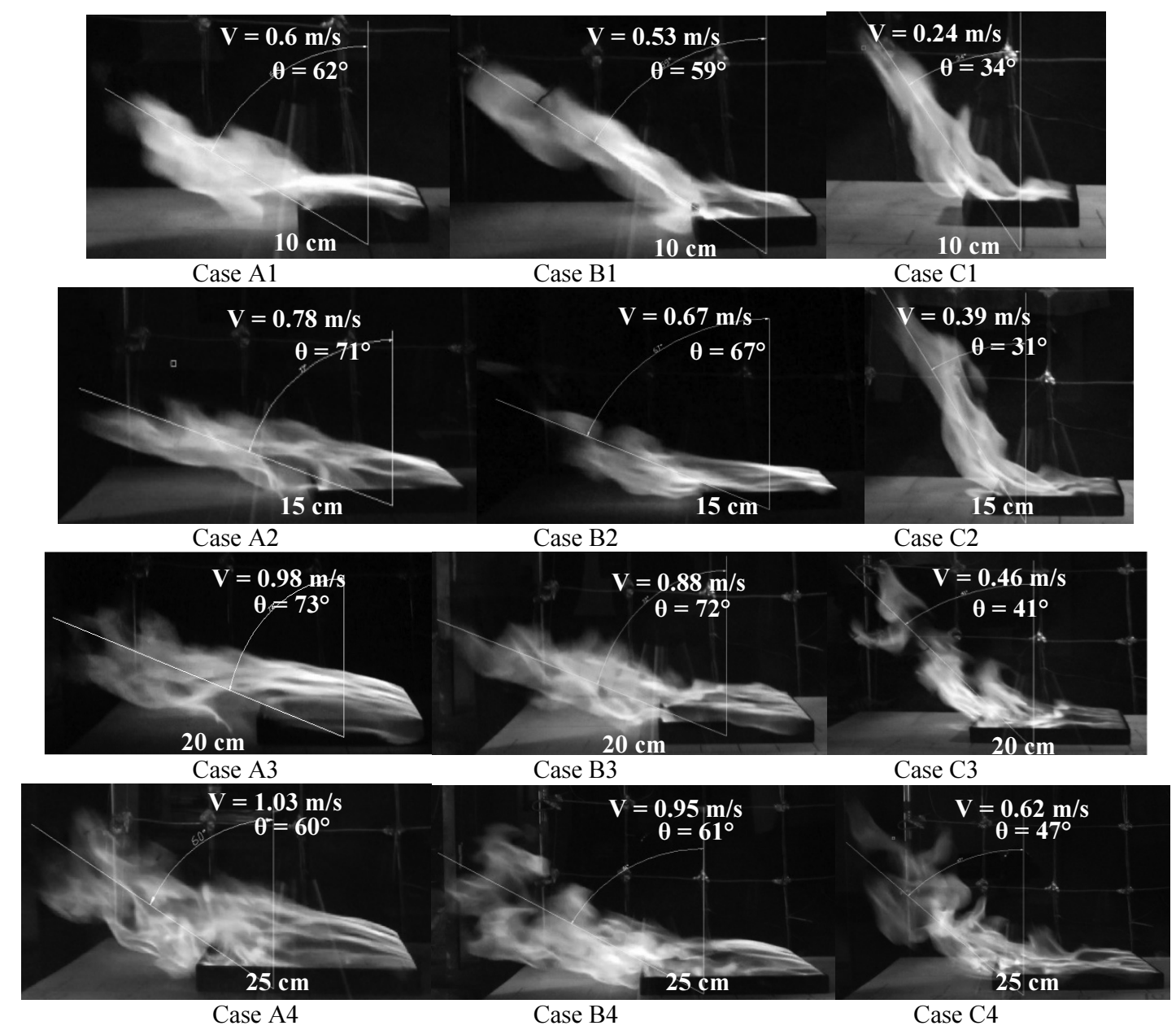

Fig. 6. Flame tilt angle $\theta$ and air speed $V$ through Door 3 in different cases (Case A1-A4: Top vent open, Door 3 Size: $0.12 \mathrm{~m}^{2}$; Case B1-B4: Top vent open, Door 3 Size: $0.24 \mathrm{~m}^{2}$; Case C1-C4: Top vent closed, Door 3 Size: $0.24 \mathrm{~m}^{2}$ ) 
The flame tilt angle is determined by the relative magnitude of the buoyancy of fire plume in vertical direction and the inertia force of air flow in horizontal direction. The relative magnitude can be expressed as a Richardson number (Ri) (Woods et al. 2006). The physical interpretation of the non-dimensional number $(R i)$ is the ratio of the total buoyant force associated with hot combustion products to the total transverse air momentum interacting with the combustion products. When the assumption of complete combustion has been applied to the mass flow rate of fuel leaving the pool, the Richardson number is calculated by the following equation (Woods et al. 2006):

$$
R i=\frac{\Delta \rho}{\rho_{a}} \frac{g L}{V^{2}},
$$

where: $\Delta \rho$ is the density difference between the air and the products of combustion; $g$ is the gravitational constant; $L$ is the stream-wise dimension of the pool; $\rho_{a}$ is the density of the air upstream of the pool; and $V$ is the transverse air speed. Assuming ideal gas behaviour and that the ratio of molecular weights of air and the products of combustion is near unity allows a more easily calculated, characteristic Richardson number to be rewritten as:

$$
R i=\left(1-\frac{T_{0}}{T_{f}}\right) \frac{g L}{V^{2}},
$$

where $T_{0}$ and $T_{f}$ are the absolute upstream air temperature and adiabatic flame temperature, respectively. In our experiments, $T_{0}$ is $278 \mathrm{~K}$ and $T_{f}$ is $973 \mathrm{~K}$, respectively.

To avoid the singularity in the quiescent case, the inverses of the Richardson number $\left(R i^{-1}\right)$ are calculated based on the experimental data, and the results are listed in Table 1. The relationship between flame tilt angle $\theta$ and $R i^{-1}$ is shown in Figure 7. It can be found that a linear relationship between flame tilt angle $\theta$ and $R i^{-1}$. As shown in Figure 7 the flame tilt angle $\theta$ increases with an increase in the value of $R i^{-1}$ and their relationship can be well approached by a linear fitting with related coefficient of 0.87 . As can be seen from the Table 1 , the value $R i^{-1}$ of $20 \mathrm{~cm}$ pool size (Case A3 and Case B3) is the maximum for the same ventilation state, the flame tilt angle $\theta$ of $20 \mathrm{~cm}$ pool size (Case A3 and Case B3) is the largest accordingly.

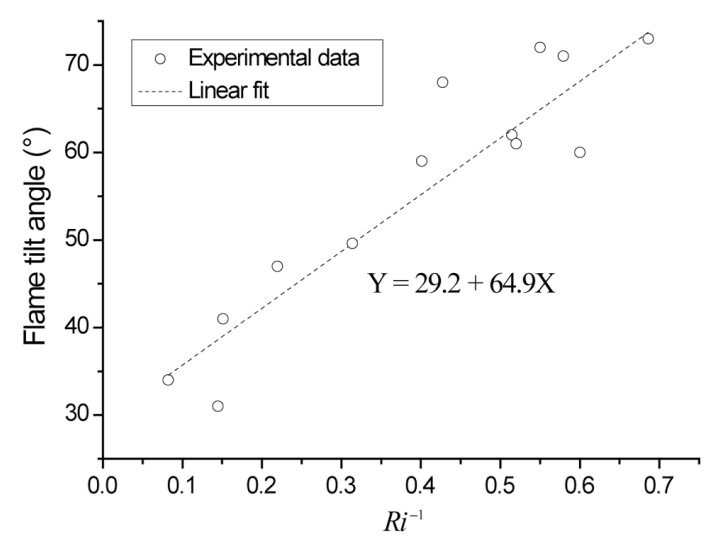

Fig. 7. Correlation of flame tilt angle $\theta$ and $R i^{-1}$

\subsection{Compartment temperature}

Twenty-five K-type fine wire thermocouples were arranged in the compartment room. The detailed locations of those thermocouples are shown in Figure 2. The thermocouple T3 was located $5 \mathrm{~cm}$ away from the left side of door 3 and was the same height level of the top of door 3 . The direction of airflow through door 3 is identified by the thermocouple T3. If the temperature of T3 is much higher than outside temperature, which indicates that the air outflows from fire room through the door 3 . In contrast, if the temperature of $\mathrm{T} 3$ is the same as the outside temperature, which indicates that the air inflows from outside. The temperatures of $\mathrm{T} 3$ in cases with top vent open and cases with top vent closed are shown in Figure 8. When the top vent of stairwell is closed, the air flows out of fire room through door 3. This is the same as the normal compartment fires. However, when the top vent of stairwell is open in the case B1-B4, the temperature of $\mathrm{T} 3$ increases rapidly at the beginning, and then decreased to the outside temperature, which indicates that the air firstly flows out of fire room and then flows into fire room from the outside. It is because a large quantity of air is sucked into fire room due to the stack effect. It also can be distinctly seen from Figure 8 that the time when temperature $\mathrm{T} 3$ began to decrease becomes earlier with increased pool size. The reason is that the stack effect occurs earlier for the bigger pool size.

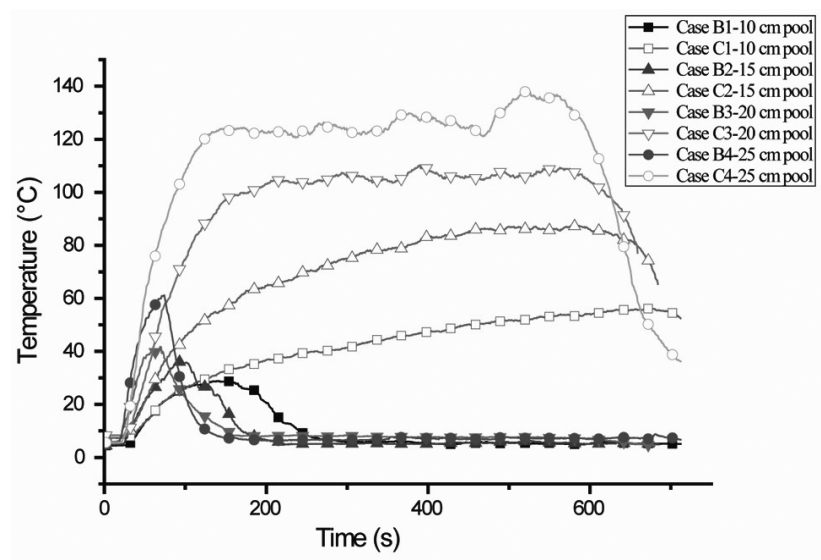

Fig. 8. Temperature of thermocouple T3 (height $0.6 \mathrm{~m}$, Door 3 left $5 \mathrm{~cm}$ ) in case B1-B4 (Top Vent: Open) and case C1-C4 (Top Vent: Closed)

The thermocouples $\mathrm{T} 1, \mathrm{~T} 6, \mathrm{~T} 11, \mathrm{~T} 16$ and $\mathrm{T} 21$ (shown in Fig. 2) were located at $0.9 \mathrm{~m}$ height and measured the temperature of the upper hot gases in the compartment. The mean temperatures of the thermocouples T1, T6, T11, T16 and T21 in a relatively steady state in different cases are shown in Figure 9. It is shown that the mean temperatures of upper hot gases in cases with top vent opened are much lower than those in cases with top vent closed. A possible explanation for this phenomenon is that the velocity of airflow into fire room is much larger under the action of stack effect. On one hand, a large amount of fresh air mixes with hot gases and cools down the temperature. On the other hand, most of smoke is sucked into the stairwell before it rises to the compart- 
ment ceiling. So the temperatures of upper hot gases are much lower in cases with top vent opened. It also can be distinctly seen from Figure 9 that the temperature in cases with top vent closed increases significantly with an increase in pool size, compared in cases with top vent open. It is possible that the hot smoke produced by fire source gathers more easily due to smaller air flow speed in cases with top vent closed.

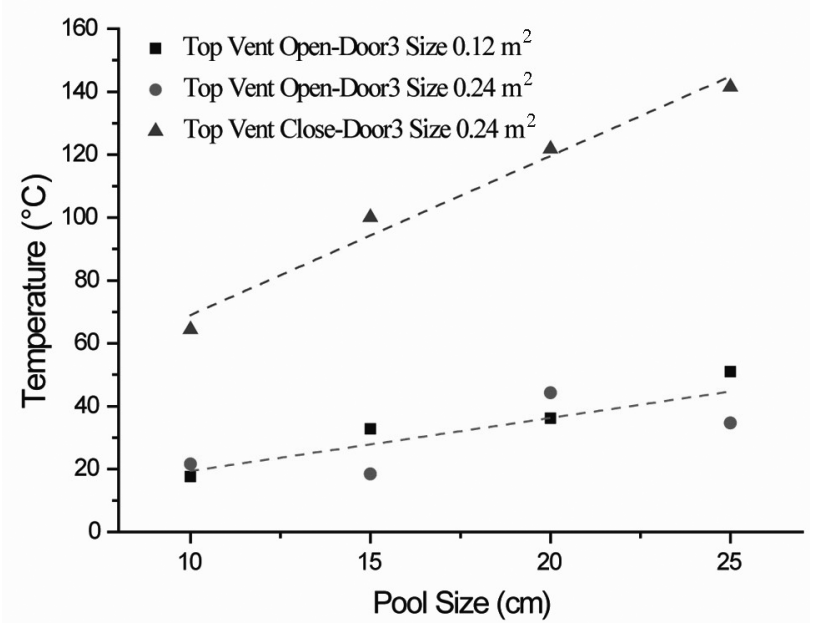

Fig. 9. The mean temperature of the upper hot gases $(0.9 \mathrm{~m}$ height) in the compartment

The hot smoke produced from fire source in fire room spread to atria and stairwell successively after ignition. The temperatures of stairwell increase and lead to the occurring stack effect which significantly influence the fire behaviours in fire room. The strength of stack effect is closely related to the temperature of stairwell, so we record the temperatures of hot smoke to analysis the air flow pattern and the influence of stack effect on fire in the compartment. Taking Case B4 (pool size: $25 \mathrm{~cm}$, top vent: open, door 3 size: $0.24 \mathrm{~m}^{2}$ ) for example, the fire room temperature, stairwell temperature and airflow speed $V$ are shown in Figure 10. As can be seen from Figure 10, the temperature in the fire room (T3 and T11) firstly increases after ignition, and then the hot smoke induced by buoyancy spreads to the atria and stairwell. At about $25 \mathrm{~s}$, the hot smoke from fire room flows in the stairwell and the temperature in the first floor of stairwell (T36) begins to rise. Then the hot smoke start to spread upward and the temperatures increase gradually in the stairwell. When the temperature of T3 (inside the door 3 ) decreases firstly at about $70 \mathrm{~s}$, which indicates that the hot smoke is no longer outflow the fire room and the fresh air is sucked into the fire room by the stack effect action. It can be concluded that at about $70 \mathrm{~s}$, the stack effect begins to occur. After more cooling fresh air flowing into the fire room, at about $80 \mathrm{~s}$, the temperature above fire source (T11) also begins to decrease. As time passed, at about $140 \mathrm{~s}$, it can be found that the temperature of T47 (located in $12^{\text {th }}$ floor of stairwell) begins to increase, which indicates that the hot smoke spread to the twelfth floor of stairwell and flow out from the top vent. Meanwhile, the temperature of T3 decreases to the out- door temperature after a long time of air cooling effect. It also can be seen that the velocity of air flow through door 3 enters the slow growth stage after a dramatic increases from $0-140 \mathrm{~s}$. From these changes in temperature and velocity in Figure 10, it can be concluded that the stack effect begins to occur at about $70 \mathrm{~s}$ and almost completely forms when the hot smokes spread to the twelfth of stairwell at $140 \mathrm{~s}$, and then all the parameters have little change, but the temperature of T11 fluctuates significantly after $350 \mathrm{~s}$, a possible explanation for this is that the heat release rate of fire source show a great fluctuation under the influence of the transverse air flow, which will be proved in the following section about mass loss rate.

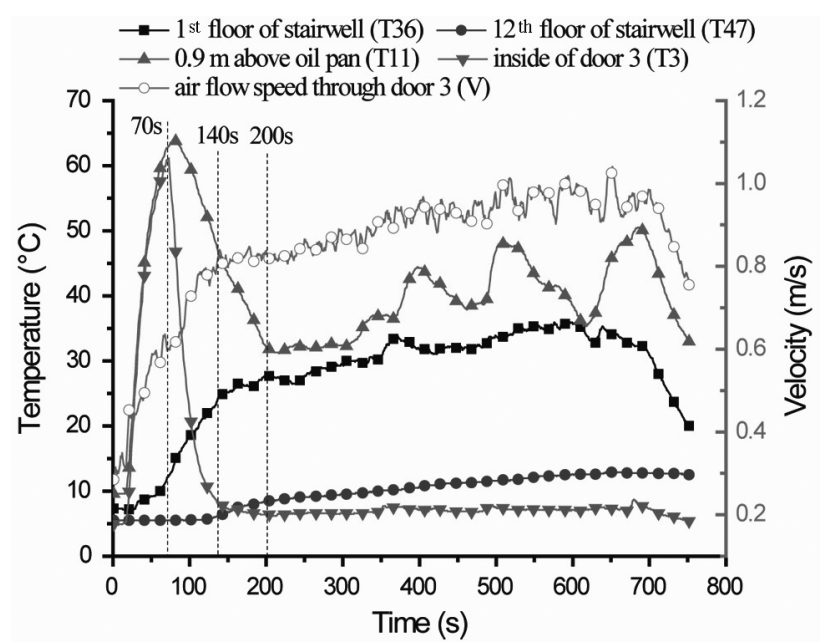

Fig. 10. Comparison of the fire room temperature T3 and T11, stairwell temperature $\mathrm{T} 36$ and $\mathrm{T} 47$, airflow speed $V$ in case B4 (pool size: $25 \mathrm{~cm}$, top vent: open, door 3 size: $0.24 \mathrm{~m}^{2}$ ) T36: the first floor of stair; T47: the twelfth floor of stair; T3: $5 \mathrm{~cm}$ away from Door 3, $0.6 \mathrm{~m}$ high; T11: $0.9 \mathrm{~m}$ above the oil pan; $V$ : air flow speed through door 3

\subsection{Mass loss rate}

The electronic balance recorded the instantaneous mass loss of methanol fuel in different cases in this experiment. Taking $25 \mathrm{~cm}$ pool size for example, the curves of mass vs. time and the mass loss rate in different cases are shown in Figure 11. It is shown from Figure 11 that before the occurrence of stack effect in the stairwell (about $70 \mathrm{~s}$ ), the mass loss rates of $25 \mathrm{~cm}$ pool size in four cases are almost same, and then the mass loss rates decrease with the strength increasing of stack effect. In the case C4 with top vent closed, from about $70 \mathrm{~s}$ to $200 \mathrm{~s}$, the mass loss rate is slightly smaller than the value in case in open space. After $200 \mathrm{~s}$, the velocity of air flow from the outside induced by natural air supply is relatively small, and so the mass loss rates in two cases are almost the same. It can be concluded that for the cases with top vent closed, after the smoke reaches the twelfth floor of the stairwell, the combustion of the pool fire achieves the relatively stable state and the heat release rate is slightly influenced by the air flow from the outside. However, in cases B4 and A4 with top vent opened, after the occurrence of stack effect, the velocity of air flow from the outside induced by the stack effect is relatively large. The mass 


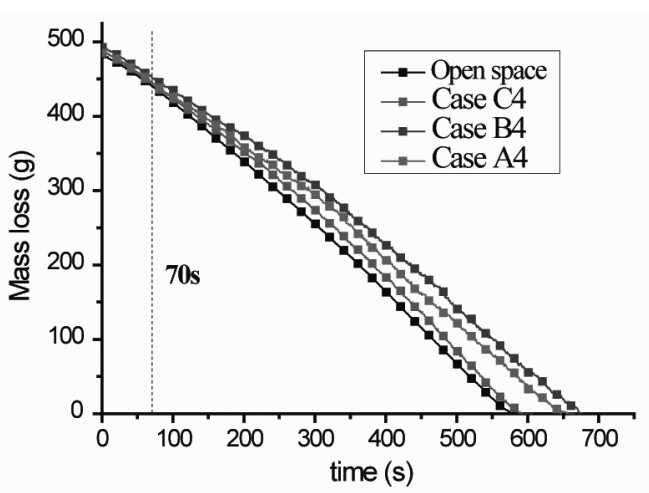

(a) mass vs. time

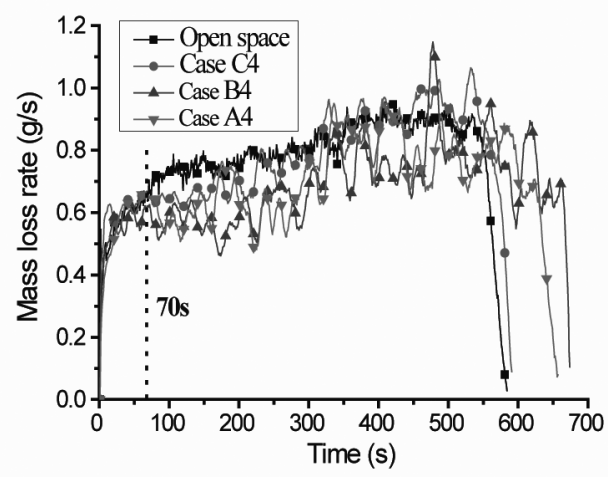

(b) mass loss rate

Fig. 11. Mass loss rate of $25 \mathrm{~cm}$ pool size in different cases (Case A4: top vent open, door 3 size: $0.12 \mathrm{~m}^{2}$; Case B4: top vent open, door 3 size: $0.24 \mathrm{~m}^{2}$; Case C4: top vent close, door 3 size: $0.24 \mathrm{~m}^{2}$ )

loss rates fluctuate significantly and the averages are smaller than that in open space, indicating a smaller heat release rate. Therefore, as seen from Figure 11, the whole burning times in open space and cases $\mathrm{C} 4$ are less than that of Case A4 and Case B4.

The fresh air sucked into fire room due to stack effect influences the burning rate of pool fire. Generically, in a single compartment, the fresh air flow has two opposing effects (Huang et al. 2009; Chen et al. 2008; Woods et al. 2006; Kumar, Naveen 2007). One is to promote combustion within the compartment and thus raise the temperature, the other is to blow away and dilute the combustible gases in the compartment and decrease the temperature, or hasten its extinction. Which effect predominates mainly depends on the airflow velocity. The average mass loss rates in steady state in all cases are plotted in Figure 12. It is obvious that the average mass loss rate increases as pool size increases. For $10 \mathrm{~cm}$ and $15 \mathrm{~cm}$ pool size, the mass loss rates in all the cases are almost the same as those in open space. However for $20 \mathrm{~cm}$ and $25 \mathrm{~cm}$ pool size, the mass loss rates in cases with top vent closed (case C3-C4) and open space are larger than those in cases with top vent opened (case A3-A4 and case B3-B4), which indicates that the second effect predominates and leads to reduce the burning rate of the methanol pool fire. This result can be supported by those data from Figure 9. It is clearly seen from Figure 9 that the temperatures of upper hot gases in fire room in case A3-A4 and case B3-B4 are very low, about $40^{\circ} \mathrm{C}$, after the strong stack effect forms.

Roh et al. (2007a, b) discovered that the burning rate of methanol pool fire with different pool length decreased with the transverse air flow velocity ranged only from 0 to $1.68 \mathrm{~m} / \mathrm{s}$. This is different with the results obtained by our experiments. From the data in Figure 6, the maximum of the velocity of air flow is $0.62 \mathrm{~m} / \mathrm{s}$ in case $\mathrm{C} 1-\mathrm{C} 4$, but the burning rate is the same as that in open space and do not decrease obviously. One possible reason is that the fire is located in a small compartment and the temperature in the room is higher when the top vent of stairwell is closed (as shown in Fig. 9). The fire-induced smoke and walls in the compartment with high temperature result in high heat feedback to fire source. This is different with the situation described in Roh's research (2007a, b). The temperature around the fire source decreased rapidly after flame tilt under the transverse air flow action in tunnel, and then the radiant heat feedback from the hot smokes and tunnel walls reduced significantly leading to decreased burning rate. The cases where the top vent of stairwell is open (case A3-A4 and case B3B4) are similar with the situation in the tunnel. The stronger air flow occurs in the compartment with two opposite doors at the two sidewalls. So the temperature around the fire source decreases obviously by the action of air speed from $0.88-1.03 \mathrm{~m} / \mathrm{s}$ (as shown in Fig. 9) and the burning rate of methanol fuel decreases in case A3-A4 and case B3-B4 (as shown in Fig. 12).

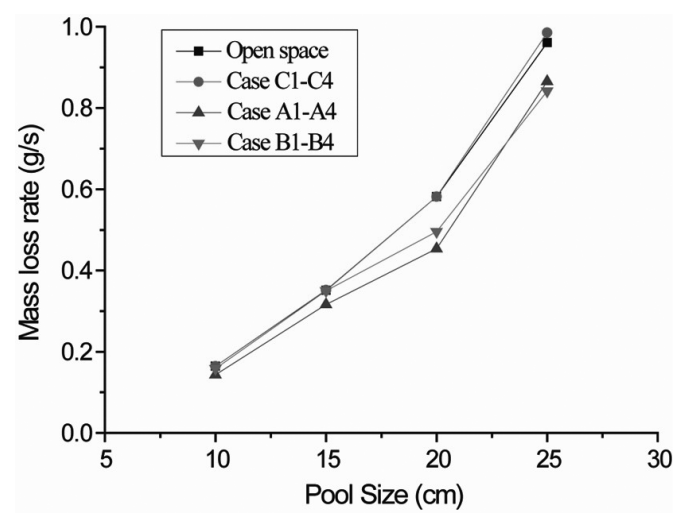

Fig. 12. Mass loss rate of different cases in steady stage (Case A1-A4: top vent open, door 3 size: $0.12 \mathrm{~m}^{2}$; Case B1-B4: top vent open, door 3 size: $0.24 \mathrm{~m}^{2}$; Case C1-C4: top vent close, door 3 size: $0.24 \mathrm{~m}^{2}$ )

The strength of stack effect influenced directly by the heat release rate determines the size of the air flow speed. Therefore, the air flow speed through door 3 and heat release rate may have a certain relationship. Tanaka et al. (2000) discovered the relationship between the plume velocity at the shaft and heat release rate of fire source located at the centre of shaft bottom as follows:

$$
\mathrm{w} \propto \sqrt{g}\left(\frac{\dot{Q}}{c_{p} \rho_{z} T_{0} \sqrt{g}}\right)^{1 / 3}\left(\frac{\mathrm{Z}}{A}\right)^{1 / 3},
$$


where: $w$ is the plume velocity at the shaft; $Z$ is the height above the source; $\dot{Q}$ is the heat release rate of the fire source; $c_{p}$ is specific heat of air at constant pressure; $\rho_{Z}$ is characteristic density of smoke at $Z ; g$ is the acceleration due to gravity; $T_{0}$ is ambient temperature; $A$ is the horizontal section area of the plume at the shaft.

It is obviously seen from the Eqn (3) that the velocity of plume at the shaft is proportional to $1 / 3$ to the heat release rate. However, in this study, the fire source located at the centre of room and the shaft was replaced by stairwell. The fresh air was sucked into fire room only through door 3. When the top vent of stairwell is open, all the hot smoke from the fire room spread to the atria and stairwell in steady state after ignition. In addition, the methanol is clean fuel, and the smoke produced during combustion is very little. So based on ideal plum theory, the mass flow rate of plum fire is approximately equal to the mass flow rate of air flow through Door 3. According to conservation of mass, the mass rate of air flow into fire room is equal to that of the plume through the horizontal section area at the shaft, as follows:

$$
\rho_{\mathrm{z}} A w=\rho_{0} S V,
$$

where: $\rho_{0}$ is ambient air density; $S$ is the size of Door $3 ; V$ is the velocity air flow into the fire room through door 3 .

Based on the state equation of ideal gas, the following relation can be obtained:

$$
T_{0} \rho_{0}=T_{\mathrm{z}} \rho_{z} .
$$

Substituting Eqns (4) and (5) into Eqn (3) yields the relationship as follows:

$$
\mathrm{V} \propto \sqrt{g}\left(\frac{\dot{Q} T_{z}}{c_{p} \rho_{0} T_{0}^{2} \sqrt{g}}\right)^{1 / 3}\left(\frac{\mathrm{z}}{A}\right)^{1 / 3} \frac{A}{S} \frac{T_{0}}{T_{z}},
$$

where $\dot{Q}$ can be calculated according to the follow equation:

$$
\dot{Q}=\lambda \dot{m} \Delta H,
$$

where: $\lambda$ is combustion efficient and can be approximately equal to 1 for the methanol; $\dot{m}$ is mass loss rate; $\Delta H$ is heat of combustion, this $\Delta H=20 \mathrm{KJ} / \mathrm{g}$.

It is obviously found from the Eqn (6) that the velocity of air flow into fire room is proportional to $1 / 3$ power of the heat release rate of fire source located at the centre of fire room in the building model. The experimental data in cases with top vent opened (case A1-A4 and case B1-B4) is shown in Figure 13. Those data indicate that the liner relationship between air speed $V$ and heat release rate $\dot{Q}^{\frac{1}{3}}$ claimed by Tanaka et al. (2000) is reliable and accurate in the stairwell. The present results can provide data and be used as a reference for the researchers and engineers of high rise building fire protection.

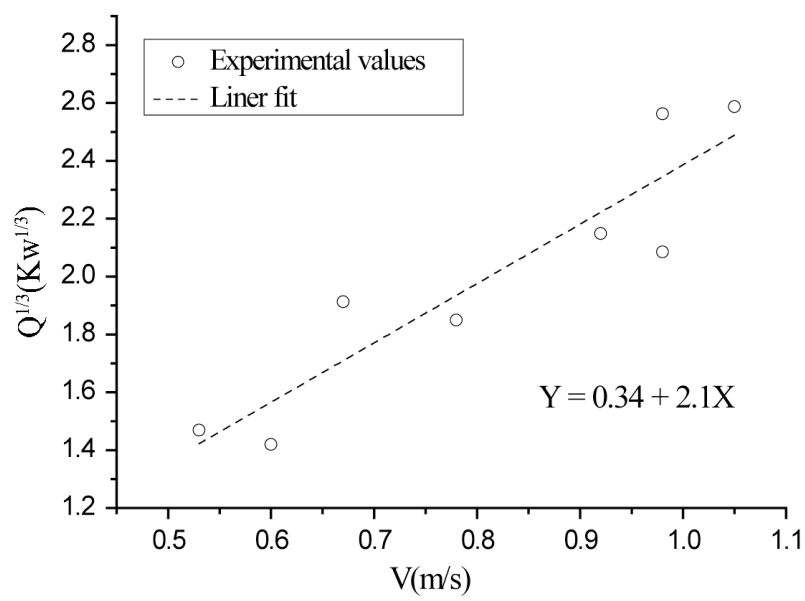

Fig. 13. The relationship between $V$ and $\dot{Q}^{\frac{1}{3}}$

\section{Conclusions}

In this paper, to study the influence of stack effect on fire in the compartment adjacent to the stairwell, a total of 12 experiments were conducted by varying the pool size (10, $15,20,25 \mathrm{~cm}$ ), top vent state (open or close) and size of door 3 on the ground floor $\left(0.12\right.$ or $\left.0.24 \mathrm{~m}^{2}\right)$ in a $1 / 3$ scaled 12-layer-stairwell configuration. The temperatures and fire properties in the compartment were investigated. The results are summarized as follows:

- The methanol flame inclines towards the direction of stairwell under the influence of stack effect after ignition. The flame tilt angle $\theta$ is influenced by the air flow and remarkably enlarged by the stack effect action. The results show that the flame tilt angle $\theta$ increases with an increase in $R l^{-1}$.

- The mean temperatures in the fire room in cases with top vent opened decrease due to the cooling effect of fresh air sucked into fire room induced by stack effect, and the time of temperature of hot smoke began to decrease is earlier with an increase in pool size. It is because that the stack effect occurs earlier and is stronger for the bigger pool size. When the hot smoke rises to the top floor, the stack effect almost completely forms and is extremely obvious. The temperatures in the fire room almost decreases to minimum and the air speed through door 3 almost increases to maximum, and then all the values do not change significantly.

- The fresh air sucked into fire room due to stack effect plays a significant role in the burning rates of pool fire. The burning rates of the methanol pool fire decrease in cases with top vent opened. The reason for this phenomenon is that the fresh air induced by the stack effect blows away and dilutes the combustible gases in the compartment. In addition, the air flow speed and heat release rate have a certain relationship. The results indicate that the velocity of air flow into fire room is proportional to $1 / 3$ power of the heat release rate in the stairwell. 


\section{Nomenclature}

$R i$ - Richardson number;

$\mathrm{g}$ - gravity acceleration $\left(\mathrm{m} / \mathrm{s}^{2}\right)$;

$Z$ - height above the source $(\mathrm{m})$;

$L$ - pool length (m);

$\Delta \mathrm{T}$ - pressure difference caused by the stack effect $(\mathrm{Pa})$;

$\dot{Q}$ - heat release rate $(\mathrm{kW})$;

$c_{p}$ - specific heat of air at constant pressure $(\mathrm{J} / \mathrm{kg} \cdot \mathrm{K})$;

$\Delta H$ - heat of combustion $(\mathrm{kJ} / \mathrm{kg})$;

$T_{0}$ - air temperature (K);

$T_{f}$ - flame temperature $(\mathrm{K})$;

$V$ - air speed through door $3(\mathrm{~m} / \mathrm{s})$;

$w$ - plume vertical velocity at the shaft $(\mathrm{m} / \mathrm{s})$;

$A$ - horizontal section area of the plume at the shaft $\left(\mathrm{m}^{2}\right)$;

$\mathrm{S}-$ size of door $3\left(\mathrm{~m}^{2}\right)$.

Greek symbols

$\Delta \rho$ - the density difference between the air and the products of combustion $\left(\mathrm{kg} / \mathrm{m}^{3}\right)$;

$\rho$ - density $\left(\mathrm{kg} / \mathrm{m}^{3}\right)$;

$\rho_{a}$ - density of the air upstream of the pool;

$\rho_{Z}$ - characteristic density of smoke at $Z$;

$\theta$ - flame tilt angle $\left(^{\circ}\right)$;

$\lambda$ - combustion efficient.

Subscript

0 - outside air;

$\mathrm{f}$ - flame;

$z$ - height above the source.

\section{Acknowledgement}

This research was supported by the National Basic Research Program of China (973 Program) under Grant No. 2012CB719700, National Natural Science Foundation of China under Grant No. 91024027 and the Fundamental Research Funds for the Central Universities under Grant No. WK2320000014.

\section{References}

Barrett, R. E.; Locklin, D. W. 1969. A computer technique for predicting smoke movement in tall buildings, Fire Technology 5(4): 299-310. http://dx.doi.org/10.1007/BF02600417

Best, R.; Demers, D. P. 1982. Investigation report on the MGM Grand Hotel Fire-Las Vegas, Nevada, November 21, 1980. National Fire Protection Association, Quincy, MA.

Chen, H. X.; Liu, N. A.; Zhang, L. H.; Deng, Z. H.; Huang, H. 2008. Experimental study on cross-ventilation compartment fire in the wind environment, Fire Safety Science 9: 907-918. http://dx.doi.org/10.3801/IAFSS.FSS.9-907

Chow, C. L. 2011. Numerical studies on smoke spread in the cavity of a double-skin facade, Journal of Civil Engineering and Management 17(3): 371-392. http://dx.doi.org/10.3846/13923730.2011.595075

Chow, C. L.; Chow, W. K. 2009. Fire safety aspects of refuge floors in supertall buildings with computational fluid dynamics, Journal of Civil Engineering and Management 15(3): 225-236. http://dx.doi.org/10.3846/1392-3730.2009.15.225-236
Chow, W. K. 2005. Building fire safety in the Far East, Architectural Science Review 48(4): 285-94. http://dx.doi.org/10.3763/asre.2005.4836

Chow, W. K.; Hung, W. Y. 2003. On the fire safety for internal voids in high rise buildings, Building and Environment 38(11): 1317-1325.

http://dx.doi.org/10.1016/S0360-1323(03)00114-8

Cooper, L. Y. 1998. Simulating smoke movement through long vertical shafts in zone-type compartment fire models, Fire Safety Journal 31(2): 85-99.

http://dx.doi.org/10.1016/S0379-7112(98)00070-8

Council on Tall Buildings and Urban Habitat. 1992. Fire Safety in Tall Buildings. New York: McGraw-HILL.

Evans, D. H.; Klote, J. H. 2003. Smoke Control Provisions of the 2000 IBC: an interpretation and application guide. IL: International Code Council.

Guo, S. D.; Yang, R.; Zhang, H. 2009. Development of a fire zone model considering mixing behavior, Journal of Thermophysics and Heat Transfer 23(2): 327-338. http://dx.doi.org/10.2514/1.41240

Guo, S. D.; Yang, R.; Zhang, H. 2010. The zone-particle model for building fire simulation, Chinese Science Bulletin 55(26): 3060-3065.

http://dx.doi.org/10.1007/s11434-010-3038-2

Huang, H.; Ooka, R.; Liu, N. A.; Zhang, L. H.; Deng, Z. H.; Kato, S. 2009. Experimental study of fire growth in a reduced-scale compartment under different approaching external wind conditions, Fire Safety Journal 44(3): 311321. http://dx.doi.org/10.1016/j.firesaf.2008.07.005

Ji, J.; Gao, Z. H.; Fan, C. G.; Zhong, W.; Sun, J. H. 2012a. A study of the effect of plug-holing and boundary layer separation on natural ventilation with vertical shaft in urban road tunnel fires, International Journal of Heat and Mass Transfer 55(21-22): 6032-6041.

http://dx.doi.org/10.1016/j.ijheatmasstransfer.2012.06.014

Ji, J.; Fan, C. G.; Gao, Z. H.; Sun, J. H. 2012b. Effects of vertical shaft geometry on natural ventilation in urban road tunnel fires, Journal of Civil Engineering and Management.

Ji, J.; Li, L. J.; Shi, W. X.; Fan, C. G.; Sun, J. H. 2013. Experimental investigation on the rising characteristics of the fire-induced buoyant plume in stairwells, International Journal of Heat and Mass Transfer 64: 193-201. http://dx.doi.org/10.1016/j.ijheatmasstransfer.2013.04.030

Klote, J. H. 1994. Fire and smoke control: an historical perspective, ASHRAE Journal 36(7): 46-50.

Klote, J. H.; Fothergill, J. W. 1983. Design of smoke control systems for buildings. US Department of Commerce, National Bureau of Standards. Washington D.C. 272 p.

Kumar, R.; Naveen, M. 2007. An experimental fire in compartment with dual vent on opposite walls, Combustion Science and Technology 179(8): 1527-1547. http://dx.doi.org/10.1080/00102200701202650

Li, Y. F.; Ji, J.; Shi, W. X.; Sun, J. H. 2013. Numerical studies on smoke spread in the cavity of a double-skin façade, Journal of Civil Engineering and Management (in Press).

Mowrer, F. W. 2009. Driving forces for smoke movement and management, Fire Technology 45(2): 147-162. http://dx.doi.org/10.1007/s10694-008-0077-1

Porch, M.; Trebukov, S. 2000. Wind effects on smoke motion in buildings, Fire Safety Journal 35(3): 257-273. http://dx.doi.org/10.1016/S0379-7112(00)00017-5 
Roh, J. S.; Ryou, H. S.; Kim, D. H.; Jung, W. S.; Jang, Y. J. 2007a. Critical velocity and burning rate in pool fire during longitudinal ventilation, Tunnel Underground Space Technology 22(3): 262-271. http://dx.doi.org/10.1016/j.tust.2006.08.003

Roh, J. S.; Yang, S. S.; Ryou, H. S. 2007b. Tunnel fires: experiments on critical velocity and burning rate in pool fire during longitudinal ventilation, Journal Fire Science 25(2): 161-176. http://dx.doi.org/10.1177/0734904107067300

Sun, X. Q. 2009. Studies on smoke movement and control in shafts and stairwell in high rise buildings: $\mathrm{PhD}$ Thesis. University of Science and Technology of China.

Tamura, G. T. 1994. Smoke movement and control in high rise buildings. National Fire Protection Association.
Tanaka, T.; Fujita, T.; Yamaguchi, J. 2000. Investigation into rise time of buoyant fire plume fronts, International Journal on Engineering Performance-Based Fire Codes 2(1): 14-25.

Woods, J. A. R.; Fleck, B. A.; Kostiuk, L. W. 2006. Effects of transverse air flow on burning rates of rectangular methanol pool fires, Combustion and Flame 146(1-2): 379-390. http://dx.doi.org/10.1016/j.combustflame.2006.02.007

Zhang, J. Y.; Ji, J.; Huo, R.; Yuan, H. Y.; Yang, R. 2006. A comparison of simulation and experiment on stack effect in long vertical shaft, Journal of Fire Science 24(2): 121135. http://dx.doi.org/10.1177/0734904106055573

Zukoski, E. E. 1995. A review of flows driven by natural convection in Adiabatic shafts. National Institute of Standards and Technology, 95-679.

Wen Xi SHI. A doctoral student of University of Science and Technology of China from September 2011 to present, and he has participated in joint training project of the University of Science and Technology of China and City University of Hong Kong in 2010. His research interest includes smoke spread and control method in high rise buildings.

Jie JI. An Associate Professor of State Key Laboratory of Fire Science, University of Science and Technology of China, and is also a life member of International Association of Fire Safety Science. He received his PhD degree in Fire Safety Engineering from University of Science and Technology of China in 2008. His main research interests include smoke movement and ventilation control method in building fires and characteristics of flame spread over surface of solid combustibles.

Jin Hua SUN. A Professor and Vice Director of State Key Laboratory of Fire Science, University of Science and Technology of China. He is also a Vice Chairman of Asia-Oceania Association for Fire Science and Technology and Director of the International Association for Fire Safety Science. He received his PhD from the University of Tokyo in 1999. To date he has authored over 200 research papers of which 100 were indexed by SCI and EI, including over 20 published in h-factor top journals and six books. His main research interests include fire dynamics and basic fire prevention technologies, large-scale evacuation and rescue in emergencies, hazardous chemical disaster prediction and prevention methods.

S. M. LO. A Professor of the Department of Civil and Architectural Engineering, City University of Hong Kong. He received his $\mathrm{PhD}$ in Architecture from the University of Hong Kong and is an Authorized Person registered under the Hong Kong Buildings Ordinance. His main research interests include building design, spatial planning for pedestrian flow and evacuation, decision support system and fire safety engineering.

Lin Jie LI. A doctoral student of University of Science and Technology of China from September 2011 to present. His research interest includes smoke spread and control method in high rise buildings.

Xiang Yong YUAN. A postgraduate of University of Science and Technology of China. His research interest includes smoke spread and control method in high rise buildings. 